\title{
Disequilibrium Trace Element Re-distribution During Garnet to Spinel Facies Transformation
}

Koga, K.T. ${ }^{1}$, Shimizu, N. ${ }^{2}$, Grove, T.L. ${ }^{3}$

1. Woods Hole Oceanographic Institution / Massachusetts Institute of Technology Joint Program in Marine Geology and Geophysics, WHOI, 360 Woods Hole Rd, Woods Hole, MA 02540-1541, USA

2. Department of Marine Geology and Geophysics, Woods Hole Oceanographic Institution, 360 Wood Hole Rd, Woods Hole, MA 02540-1541, USA

3. Department of Earth, Atmospheric, and Planetary Sciences, Massachusetts Institute of Technology, Cambridge, MA 02143 , USA

An experimental investigation has been performed to examine trace element re-distribution during garnet-spinel facies transformation that is characterized by the reaction,

$$
\text { olivine + garnet } \rightarrow \text { clinopyroxene (cpx) + orthopyroxene (opx)+ spinel, }
$$

using minerals from natural peridotite. We find that the trace element abundance in cpx and opx formed as products of garnet breakdown is "inherited" from the trace element abundance of the reactant garnet.

Evidence for trace element disequilibrium is preserved in naturally-occurring minerals in mantle rocks, suggesting that the disequilibrium trace element re-distribution may be a significant process and could be used to infer the thermal history of the mantle sample. For example, porphyroclastic pyroxenes from the Horoman peridotite, Japan, show compositional zoning consistent with a model of pyroxene growth that occurred along with garnet break down (Takazawa et al., 1996). Large variations in trace element abundance observed in these pyroxenes can be modeled as the disequilibrium trace element re-distribution, and imply a rapid reaction rate for garnet break down.

Experiments were conducted using mixtures of olivine (Fo89.8), garnet (Py72.2Alm15.9 Gr9.9Uv2.0), and clinopyroxene (Wo45.7En48.9Fs5.4), hand-picked from a garnet lherzolite xenolith (TM0) from Pali Aike, Chile. This starting materials was chosen as a representative primitive upper mantle (Hart and Zindler, 1986). Experiments were performed at $1360^{\circ} \mathrm{C}$, and at pressures of 1.8, 2.0, and 2.4 GPa. Experiment duration was varied from 2 to 170 hours to obtain time-series data at each pressure. Progress of the reaction was measured on a polished surface of a quenched sample by digital processing of back scattered electron images (BSE) and $\mathrm{Al}, \mathrm{Mg}, \mathrm{Ca} \mathrm{X}$ ray images. Trace element concentrations were measured by ion microprobe. Each ion microprobe beam crater was inspected by an optical microscope and an electron microprobe. This procedure was necessary to exclude analyses that sampled multiple phases due to the small size of reacted mineralgrains.

The following textural and petrological observations are relevant for understanding the redistribution of trace elements in opx and cpx of natural mantle rocks. (1) The transformation reaction always begins at olivine-garnet interface with no grain-size related preference on reaction site, and no reaction was observed within garnet. (2) A first-order reaction model (i.e. decay equation, described in Avrami, 1940) adequately explains the time dependence of reaction progress. The model predicts geologically fast completion of the reaction. Using the model, garnet to spinel facies transformation is complete in 4 years at $2.4 \mathrm{GPa}, 1360^{\circ} \mathrm{C}$ and 60 hours at $1.8 \mathrm{GPa}$ at $1360^{\circ} \mathrm{C}$. (3) The initial reaction rate approaches zero at 2.6 to $2.7 \mathrm{GPa}$, implying that the garnet to spinel facies boundary for this composition occurs near this pressure. This reaction boundary has been reported to have a strong compositional dependence on $\mathrm{Fe}$ and $\mathrm{Cr}$ (e.g. O'Neill, 1981). This 
experimental result is the most relevant for the naturally-occurring mantle subsolidus reactions, because it used natural starting materials.

Trace element abundance measured in newly formed opx and cpx in coarse-grained parts of experimental charges demonstrate that reactant phases inherit garnet-like trace element abundances. For instance, opx and cpx grains have $\mathrm{Ti}, \mathrm{Y}, \mathrm{Sr}$, and $\mathrm{Zr}$ concentrations (580-1300 ppm, 50-75 ppm, 0.9-5.0 ppm, and 10-30 ppm) similar to original garnet. Newly formed cpx shows a rare earth element (REE) pattern that differ from the starting garnet and cpx (Figure 1). Finally, newly formed opx shows variation of $\mathrm{Ti}$ and $\mathrm{Sr}$ abundance that is intermediate between the starting abundance in garnet and cpx.

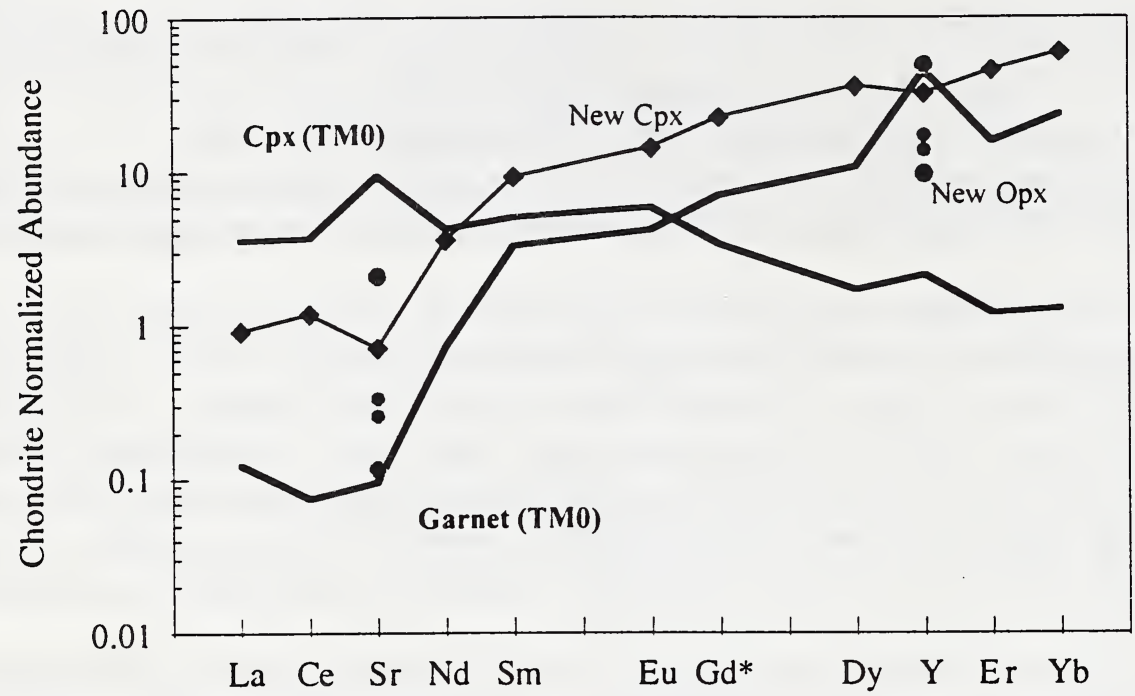

Figure 1. Chondrite normalized trace element abundance is plotted against order of compatibility. Thick lines indicates starting compositions and a thin line is for newly formed cpx. Dark circles shows new opxs.

While inheriting garnet-like trace element abundance, trace element distribution between cpx and opx is in disequilibrium. For instance, $\mathrm{Ti}$ concentration in cpx and opx can not be the same, because cpx/opx partition coefficient for $\mathrm{Ti}$ is approximately 3 (e.g. Kelemen et al., 1993). The results show that $\mathrm{Ti}$ concentrations in $\mathrm{cpx}(\sim 800 \mathrm{ppm})$ and opx $(\sim 600 \mathrm{ppm})$ are different by $20 \%$. $\mathrm{Ti}$ concentrations in cpx and opx are essentially the same. Therefore, cpx and opx are in disequilibrium for Ti. Other trace elements such as $\mathrm{Sr}, \mathrm{Zr}, \mathrm{Y}$, and REE behave similarly.

Despite the evidence of disequilibrium distribution of trace elements, newly formed cpx and opx are equilibrated for major elements. The opx/cpx thermometer (Andersen et al., 1993) based on major element composition accurately determines the experimental condition confirming equilibria among the newly formed phases.

The differences in diffusivities between major and trace elements may influence the disequilibrium re-distribution. However, our results show that disequilibrium trace element redistribution is not simply diffusion controlled process. For example, $\mathrm{Sr}, \mathrm{La}$, and $\mathrm{Ce}$ are large atoms and they likely diffuse slower than major elements such as $\mathrm{Mg}, \mathrm{Ca}$, and $\mathrm{Si}$. Qualitatively, the observations of disequilibrium distribution of trace elements are expected. Nonetheless, diffusion studies in cpx reports similar diffusivity for $\mathrm{Sr}$ and $\mathrm{Mg}-\mathrm{Ca}$ exchange at high pressure condition 
(Brady and McCallister, 1983; Sneeringer et al., 1984). Then, when cpx/opx thermometer shows the equilibration, Sr should be distributed according to the partition coefficient. Our experimental results, in contrast, show disequilibrium distribution of $\mathrm{Sr}$ and equilibrium distribution of $\mathrm{Ca}$ since the thermometer strongly relies on $\mathrm{Ca}$ concentration of cpx and opx.

Our experimental results demonstrate that disequilibrium distribution of trace elements will occur in opx and cpx reactants during the garnet breakdown. In nature, time dependent processes will operate to modify these disequilibrium trace element abundances. Once crystals are formed, solid state diffusion will be the primary mechanism for achievement of equilibrium. If a spherical $\mathrm{cpx}$ is $2 \mathrm{~cm}$ in diameter, it will take 15 million years to equilibrate at conditions of $2 \mathrm{GPa}$ and $1200^{\circ} \mathrm{C}$ for $\mathrm{Sr}$. If the pyroxene stays in the mantle for sufficiently long time, disequilibrium distribution is not important. However, if a piece of the mantle is brought to the surface shortly after garnet to spinel facies transformation, opx and cpx can preserve a disequilibrium distribution of trace elements.

This disequilibrium trace element distribution may have significant impact for mantle petrologic processes. Often mantle rocks record trace element signals of multiple processes including melting, metasomatism, and subsolidus reactions. Our experimental result may provide mechanism for modeling mantle rocks with mineral compositions that are not in equilibrium between phases.

\section{References}

Andersen, D. J., Lindsley, D. H., and Davidson, P. M., 1993, QUILF: A PASCAL program to assess equilibria among $\mathrm{Fe}-\mathrm{Mg}-\mathrm{Mn}-\mathrm{Ti}$ oxides, pyroxenes, olivnie, and quartz: Computers and Geosciences, v. 19, p. 1333-1350.

Avrami, M., 1940, Kinetics of Phase Change. II: Journal of Chemical Physics, v. 8, p. 212-224.

Brady, J. B., and McCallister, R. H., 1983, Diffusion data for clinopyroxenes from homogeneization and self-diffusion experiements: American Mineralogist, v. 68, p. 95-105.

Hart, S. R., and Zindler, A., 1986, In Search of a Bulk-Earth Composition: Chemical Geology, v. 57, p. 247-267.

Kelemen, P. B., Shimizu, N., and Dunn, T., 1993, Relative depletion of niobium in some arc magmas and the continetal crust: partitioning of $\mathrm{K}, \mathrm{Nb}$, La and Ce during melt/rock reaction in the upper mantle: Earth and Planetary Science Letters, v. 120, p. 111-134.

O'Neill, H., St.C., 1981, The transition between spinel lherzolite and garnet lherzolite, and its use as a geobarometer: Contrib. Mineral. Petrol., v. 77, p. 185-194.

Sneeringer, M., Hart, S. R., and Shimizu, N., 1984, Strontium and samarium diffusion in diopside: Geochimica et Cosmochimica Acta, v. 48, p. 1589-1608.

Takazawa, E., Frey, F., Shimizu, N., and Obata, M., 1996, Evolution of the Horoman Peridotite (Hokkaido, Japan): Implications from pyroxene compositions: Chemical Geology, v. 134, p. 3-26. 